\section{Sergio Zermeño, Ensayos amargos sobre mi país. Del 68 al nuevo régimen, cincuenta años de ilusiones}

Por Nicolás Dip ${ }^{1}$

\section{I}

Si la Argentina está plagada de conmemoraciones, jornadas, eventos y publicaciones por el centenario de la Reforma Universitaria de 1918, México vive una situación análoga al cumplirse este año el cincuentenario del movimiento estudiantil de 1968. El nuevo trabajo de Sergio Zermeño, publicado por Siglo XXI bajo el título Ensayos amargos sobre mi país. Del 68 al nuevo régimen, cincuenta años de ilusiones (2018), se enmarca en una gran cantidad de ediciones y reediciones que vuelven sobre ese período de la historia reciente, marcado por la represión del 2 de octubre en la Plaza de las Tres Culturas de Tlatelolco. Desde esta primera aproximación, el libro puede ser leído como una suerte de memorias críticas y nostálgicas de un reconocido intelectual mexicano que tras un derrotero de medio siglo puede reflexionar desde una doble posición. En 1968, Zermeño estudiaba sociología en la Universidad Nacional Autónoma

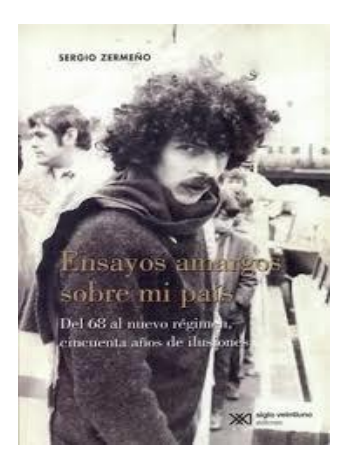

contemporánea de América Latina y sobre la cambiante trayectoria de su izquierda en el marco de la compleja cultura política del país. A esto se suma, que el trabajo no es un simple retorno autocrítico a 1968, sino un abordaje que cruza la experiencia del movimiento estudiantil de esos años con el triunfo electoral de Morena y el arribo a la presidencia de Andrés Manuel López Obrador, luego de fallidos intentos teñidos por escándalos y denuncias de fraudes electorales.

\section{II}

¿Por qué el libro de Zermeño constituye un ejercicio de sociología política? Porque su trabajo busca desentrañar el derrotero del movimiento estudiantil de 1968 en el marco de dos tendencias que nutrieron a un orden político-cultural que no deja de retrotraerse a la Revolución de 1910. Los dos pilares de la excepcionalidad mexicana: la fascinación por el vértice y el desafio de articular fuerzas disimbolas. Ambos aspectos que constituyen una estructura u orientación socio-política que el autor cree devaluatorio nombrar sólo "priista", porque en realidad es "nacional, popular y empresarial, de la misma manera que el orden argentino es irrenunciablemente peronista" (p.77). México para Zermeño: un país con morfología particular y compleja que no puede ser fácilmente asimilable a otras realidades. Se puede usar el rótulo de populismo o nacionalismo para generalizar y englobar distintos contextos, pero en Ensayos amargos sobre mi país esas experiencias resaltan por sus particularidades y estilos autóctonos.

Este enfoque socio-político es el que conecta a los seis artículos del libro y el que el cientista social elige para leer retrospectivamente su protagonismo y el derrotero de su generación en los sesenta. En relación a este punto, lo que sobresale es la aparente paradoja de un movimiento estudiantil que dinamita sus ribetes libertarios, democráticos y utópicos al caer en esa especie de doble pecado de la cultura política

Nacional de Investigaciones Científicas y Técnicas (CONICET). Autor de Libros y alpargatas. La peronización de estudiantes, docentes e intelectuales de la UBA 1966-1974 (Prohistoria, 2018).
${ }^{1}$ Doctor en Historia y Licenciado en Sociología por la Facultad de Humanidades y Ciencias de la Educación de la Universidad Nacional de La Plata (UNLP). Becario postdoctoral del Consejo 
mexicana, por su incapacidad de articular alianzas más amplias, pero sobre todo por su mímesis con el adversario: el Estado. Su fascinación por el vértice no hizo más que su aparato organizativo estudiantil más importante, el Consejo Nacional de Huelga, reprodujera la estructura vertical y autoritaria de la institución estatal. De esta manera, sus sectores dirigentes de izquierda radicalizados no pudieron sostener más que precariamente sus articulaciones con otras vertientes que confluyeron en el 68 y cayeron en lo que el autor caracteriza como el extremo grotesco de la política mexicana: la lógica del suicida y el asesino: "las amplias alianzas, al no poder subsistir por la heterogeneidad de sus integrantes, buscan un resultado inmediato antes que las escisiones las debiliten y caen en la confrontación, en el todo o nada, el águila o el sol: 'derroco al gobierno o me matan'. Del lado del déspota: 'o acabo con estos alzados o me tumban”' (p.22).

El libro no oculta en ningún momento que su interpretación historiográfica está mediada por su pertenencia generacional, como incluso queda de manifiesto en la propia tapa, donde se observa un Zermeño sesentero, joven y desafiante. Pero donde el autor visualiza excepcionalidad y no la hay es en la lectura que realiza del movimiento estudiantil mexicano al que diferencia de otras partes del mundo por una primacía de la política que lo llevó a la pérdida de sus contenidos culturales, a estructuras organizativas jerárquicas y a una ajenidad hacia los problemas de la universidad y la educación superior. En realidad, esta supuesta particularidad no sería tal si se recopila en otros países de Latinoamérica un conjunto de visiones que comparten ex militantes de los años sesenta y setenta que abordaron retrospectivamente su historia, luego de convertirse en reconocidos intelectuales. Más allá de los matices y sus itinerarios personales, trabajos como los de Oscar Terán (1991) y Beatriz Sarlo (2001) en el caso argentino o el de Manuel Antonio Garretón (1985) en el chileno, sostienen una hipótesis similar: las formas y contenidos políticos que transitaron los grupos radicalizados del

\footnotetext{
${ }^{2}$ Los trabajos de Revueltas en torno a la universidad fueron compilados póstumamente en México 68. Juventud y Revolución (1978).
}

movimiento estudiantil y la universidad no hicieron más que disolver las cuestiones culturales e intelectuales. De todas maneras, como dice el propio Zermeño, las hipótesis son estacas clavadas en el camino para luego medir los propios errores, pero también instrumentos de provocación para generar argumentaciones y avanzar en la discusión (p.10). Por esta razón, el tema de la disolución de los ámbitos específicos por la primacía de la política no deja de ser una controversia abierta, incluso cuando el propio autor de Ensayos amargos sobre mi país sostiene que en la etapa de actividad del movimiento estudiantil de 1968, el intelectual de izquierda José Revueltas insistió mucho respecto a los problemas internos de la institución universitaria ${ }^{2}$.

\section{III}

Pero el libro de Zermeño también es un ejercicio de sociología política porque no es una simple lectura del movimiento estudiantil, sino de la propia trayectoria de la izquierda. Itinerario que además es abordado en el marco de una excepcionalidad de la historia reciente de México. A diferencia de la mayoría de países latinoamericanos, sus tumultuosos años sesenta no condujeron al poder a la corporación militar. Luego de las intensas represiones de 1968 y 1971, a fines de la última década una reforma política legalizó a los partidos y grupos de izquierda, con la intención de fortalecer el andamiaje partidista, parlamentario y electoral. Así, mientras en la región la izquierda se replegaba a ámbitos discretos en el plano social y comunitario frente a regímenes dictatoriales, en México sus sectores más importantes no hicieron más que volver a robustecer la obsesión por el Estado fuerte, el centralismo y la cultura estatal. Tendencia reforzada a los pocos años con las teorías del tránsito a la democracia fomentadas por Estados Unidos, donde se enfatizaba la primacía de las instituciones.

En esta cuestión volvemos otra vez a la gran estaca que estructura las hipótesis de Zermeño sobre la política de su país: la fascinación por el 
vértice. Porque lo que aparece como un intento de hilvanar la apertura del último cuarto del siglo $\mathrm{XX}$, es en realidad una reflexión de un período mucho más amplio, donde la izquierda tuvo que hacer frente a una situación muy propia de la historia mexicana: las condensaciones instantáneas y transitorias de fuerzas disimbolas (p.74). La presencia de un Estado poderoso daría la impresión de no dejar otra alternativa para su conquista que la creación de frentes amplios con actores heterogéneos, los cuales pueden tener momentos de auge, pero están siempre al borde de la implosión y la fragmentación. Así, Zermeño eslabona cuatro grandes acumulaciones que interpelaron o involucraron de alguna manera a la izquierda, desde el llamado callista a la unidad de todas las fuerzas que remató en la creación del Partido de Estado y en la gesta nacionalista del cardenismo, pasando por el Movimiento de Liberación Nacional en pleno auge de la Revolución Cubana, la irrupción del Partido de la Revolución Democrática encabezado por el hijo del general Cárdenas, hasta la actual constitución de Morena y el triunfo presidencial de López Obrador. De esta manera aparece, en Ensayos amargos sobre mi país, el siglo XX y XXI mexicano, resumido en cuatro condensaciones y en una sentencia: la izquierda no ha sabido construir política por fuera de la fascinación por el vértice.

\section{IV}

El título y subtítulo del libro de Zermeño aluden a dos palabras en apariencia contradictorias: amargura e ilusión. Pero en este caso la lectura amarga de la cultura política mexicana no lo lleva una actitud condenatoria de su país y de la izquierda, sino a una nueva pregunta donde asoma el brío de las ilusiones perdidas: “¿resultará el triunfo de Morena un lomerío desde el que se vislumbre un futuro esperanzador?" (p.10). La respuesta es una nueva hipótesis que funciona como estaca, pero como provocación a la vez. Para el autor, el futuro de la experiencia que encabeza López Obrador depende de su capacidad de expresar una alianza que apueste a la construcción de una izquierda social (p.84). A una condensación donde la obsesión no sea la fascinación por el vértice, sino la necesidad de desenvolverse en un plano basista y en la reconstrucción de una sociedad civil popular, democrática y participativa.

El problema de fondo que está latente en Ensayos amargos sobre mi país es el desafío de recuperar y fortalecer el tejido social frente a las tendencias corporativas de todo tipo de la sociedad mexicana. En este punto, se comprende la alusión nostálgica que hace el autor a la línea de masas del maoísmo autóctono, el cual tras la experiencia novedosa de la Liga Comunista Espartaco encabezada por Revueltas y la represión de 1968, se lanzó a una política alejada de las estrategias tradicionales del PC, en pos de una acción orientada a construir con y desde la comunidad. A lo que se suma el retorno al clásico Cambiar el mundo sin tomar el poder de John Holloway (2002) y a esa discutida máxima de que no es desde el Estado y las mediaciones políticas donde se logra una transformación duradera en lo social.

Sin embargo, estas rememoraciones y citas de Zermeño no tienen que hacer confundir sobre su postura ante los desafíos políticos y sociales actuales, a los que lee también a la luz de la desarticulación de los regímenes sudamericanos de mirada a la izquierda, frente a las oleadas derechistas (p.105). A su entender, el gobierno de Morena llega tarde, pero, a la vez, es una posibilidad de reiniciar una nueva corriente que sea capaz de enmendar los vicios y desvíos burocráticos de los ciclos precedentes, los cuales parecen finalmente asimilarse a los pasos perdidos de la izquierda mexicana: fascinación por el vértice, burocratización, dinamitación de alianzas y sectores movilizados. $\mathrm{La}$ excepcionalidad mexicana en este punto se vuelve una sinécdoque, ante la cual el autor no elije contraponer Estado a lo social, sino una mirada que sea capaz de articular las instancias institucionales con una verdadera reconstrucción de las bases comunitarias y de la vida de las personas en sus espacios cotidianos. Entre estacas y provocaciones, finalmente la ilusión termina siendo grande, aunque como reconoce el autor de los ensayos, la amargura siempre espera. 
Bibliografía

- Garretón, Manuel Antonio, y Javier, Martínez, Biblioteca del movimiento estudiantil, Santiago de Chile, Ediciones Sur, 1985.

- Revueltas, José, México 68. Juventud y revolución, Ciudad de México, Ediciones Era, 2016 [1978].

- Sarlo, Beatriz, La batalla de las ideas, Buenos Aires, Ariel, 2001.

- Terán, Oscar, Nuestros años sesentas, Buenos Aires, Punto Sur, 1991.

- Zermeño, Sergio, Ensayos amargos sobre mi país. Del 68 al nuevo régimen, cincuenta años de ilusiones, Ciudad de México, Siglo XXI, 2018. 